\title{
DETERMINANTES DA PREPARAÇÃO INDEPENDENTE DOS ALIMENTOS POR NONAGENÁRIOS E CENTENÁRIOS DURANTE A COVID-19: ESTUDO
}

\section{AMPAL}

Liziane da Rosa Camargo*; Escola de Medicina da PUCRS, Porto Alegre, Brasil; lizicamargo.nutri@gmail.com Josemara de Paula Rocha; Escola de Medicina da PUCRS, Porto Alegre, Brasil; josemara.rocha@hotmail.com Ângelo José Gonçalves Bós*; Escola de Medicina da PUCRS, Porto Alegre, Brasil; angelo.bos@pucrs.br

\section{RESUMO}

Introdução: Preparação independente do alimento é parâmetro importante na avaliação funcional de nonagenários e centenários. O isolamento e a depressão podem desestimular o preparo durante a pandemia da COVID-19. Objetivo: Investigar a manutenção da preparação dos alimentos em nonagenários e centenários durante a COVID-19. Métodos: Estudo transversal e descritivo com nonagenários e centenários da coorte Atenção Multiprofissional ao Longevo (AMPAL), entrevistados entre abril e agosto/2020 por smartphone. Questionou-se quem preparou os alimentos, características sociodemográficas, sintomas depressivos (escala de depressão geriátrica), perda ponderal e desempenho cognitivo (memória imediata, temporal, espacial e evocação). Resultados: Participaram 58 nonagenários e centenários. O preparo das refeições foi realizado por familiares em $51,7 \%$, não-familiares em $34,5 \%$ e participantes em $13,8 \%$. Somente em $15 \%$ dos participantes houve modificação desse hábito durante a pandemia. Dos participantes que preparavam as refeições (8), 25\% tinham sintomas depressivos, 87,5\% eram mulheres, $50 \%$ morava sozinho, $62,5 \%$ viúvos, $62,5 \%$ idade entre $90-94$ anos, $37,5 \%$ perdeu peso, $37,5 \%$ manteve e $25 \%$ aumentou; e 7 responderam sobre a cognição: $100 \%$ acertou todas as questões da memória imediata e espaciais, $85,7 \%$, todas as temporais, e $57,1 \%$ todas da evocação. Conclusão: Poucos nonagenários e centenários prepararam a refeição durante a pandemia, essa função foi realizada principalmente por familiares e não-familiares. Dos participantes que preparam a sua comida, metade morava sozinha, tinham entre 90-94 anos, maioria mulheres e viúvas, com número expressivo de perda de peso, apesar de parte manter ou ganhar peso. Uma parcela desses idosos têm sintomas depressivos, entretanto, maioria apresentou a memória preservada.

Palavras-chaves: Idoso de 80 Anos ou mais; Cooking; Infecções por Coronavirus.

Agradecimentos: O presente trabalho foi realizado com o apoio da Coordenação de Aperfeiçoamento de Pessoal Nível Superior - Brasil (CAPES) - Código de Financiamento 001. 